\title{
O ambiente na educação infantil e a construção da identidade da criança
}

Silvia Helena Vieira Cruz

Rosimeire Costa de Andrade Cruz

\section{Resumo}

O papel desempenhado pelo ambiente na pedagogia da infância será tratado na perspectiva de Loris Malaguzzi, considerando as dimensões éticas e estéticas da sua obra sobre a educação infantil em Reggio Emilia, na Itália. Destaca-se a ideia do ambiente como terceiro educador, enfatizando o papel das relações estabelecidas entre adultos e crianças e entre as próprias crianças, assim como a participação de brinquedos, livros, quadros e demais objetos culturais nessas relações. Os elementos da constituição da identidade pela criança, propostos por Henri Wallon, reforçam a importância das interações e do meio nesse processo, o que possibilita um diálogo entre as contribuições teóricas wallonianas e as ideias defendidas pelo educador italiano. 


\section{Abstract \\ The role of the environment in early childhood education and the formation of the child's identity}

This paper presents the environment's role on early childhood education in the perspective of Loris Malaguzzi, considering the ethical and aesthetic dimensions of his work over the early childhood education in Reggio Emilia, Italy. It emphasizes the idea of the environment as a third educator, underlining the role played by relationships children maintain among themselves and with adults, as well as the part taken by toys, books, paintings and other cultural objects in these relationships. The elements used by children to build their identity, according to Henri Wallon, reinforce the importance of the interactions and of the environment in this process, which allows a dialogue among Wallon's theoretical contributions and the ideas defended by the italian educator.

Keywords: school environment; early childhood education; personal identity.

\section{Introdução}

O ambiente tem um papel muito importante na pedagogia voltada para as crianças pequenas e, portanto, recebe a atenção de muitos autores do campo da educação infantil, tais como Barbosa (2006), Forneiro (1998) e Oliveira-Formosinho (2011). É consenso, para esses estudiosos, que o ambiente determina, em grande parte, a forma de sentir, pensar e agir das pessoas.

É oportuno enfatizar, aqui, a distinção entre os termos espaço e ambiente. A palavra ambiente refere-se ao espaço físico (caracterizado, por exemplo, pelo tamanho, pelos objetos, pelos materiais didáticos, pelo mobiliário e pela decoração) acrescido das relações que nele são estabelecidas (incluindo os afetos, os conflitos e as ambiguidades existentes nas trocas entre as crianças, entre estas e os adultos e entre estes). Por meio do espaço físico, a criança é capaz de estabelecer relações entre as pessoas e o mundo, convertendo-o em cenário para as emoções. Essa qualificação do espaço físico é o que o transforma em ambiente (Forneiro, 1998; Horn, 2004).

A organização do ambiente da instituição de educação infantil nunca é neutra, mas reveladora da concepção pedagógica e dos princípios predominantes sobre educação, criança e processos de ensino e aprendizagem. Como destacam Barbosa e Horn (2001), a organização do espaço é, em primeiro lugar, resultante da leitura que o professor faz do grupo pelo qual é responsável e de suas necessidades. Assim, é preocupante o fato de diversas pesquisas apontarem que, "na educação infantil, é comum os arranjos espaciais não permitirem a interação entre as crianças, impossibilitando sua apropriação dos espaços através de objetos, desenhos e nomes" (Horn, 2004, p. 27). 
Em alguns lugares, os ambientes que compõem a unidade de educação infantil parecem dizer às crianças que eles não lhes pertencem, pois a "decoração" está fora de seu campo visual (não pode ser tocada!) e não inclui fotos ou produções delas, o armário é fechado, e tudo precisa da autorização da professora para ser usado.

Ao contrário disso, as crianças "querem o lugar da creche [e da pré-escola] como um lugar de brincadeira, um lugar de liberdade, um lugar de movimentos, um lugar de encontros e um lugar para estar a sós" (Agostinho, 2003, p. 10). Na mesma direção, a pesquisa realizada por Evangelista (2016, p. 9) revela que as crianças "anseiam por um espaço mais colorido, onde possam brincar, movimentarse, ser mais livres, onde suas individualidades sejam respeitadas, possam fazer amizades e ter contato com a natureza".

\section{Uma perspectiva inovadora sobre o ambiente}

No campo da educação infantil, a pedagogia desenvolvida no norte da Itália tem sido forte referência para muitos países, entre os quais o Brasil. Essa pedagogia nos inspira tanto pela grande produção bibliográfica e audiovisual já acumulada como pelo que é possível constatar nas visitas aos nidi e às scuole dele infanzia, que correspondem às creches e pré-escolas brasileiras. Atualmente, muitos autores italianos nos falam sobre uma gama de temas centrais para um trabalho pedagógico de qualidade, tais como a concepção de criança, a programação, a documentação, o trabalho com projetos e a relação com as famílias. Centraremos aqui a atenção nas contribuições acerca do papel dos ambientes para a educação das crianças, especialmente, nas ideias de Loris Malaguzzi, o educador que conduziu a grande revolução que aconteceu na educação das crianças a partir do término da Segunda Guerra Mundial.

Na abordagem construída em Reggio Emilia, desde o início, a preocupação com a qualidade do contexto no qual acontece a educação de crianças pequenas decorre da crença no direito da criança a um ambiente de qualidade e da ideia do espaço ${ }^{1}$ como "terceiro educador". Carla Rinaldi (2014, p. 145-146) destaca essas ideias de Loris Malaguzzi e relata:

\footnotetext{
Quando comecei a trabalhar nas escolas municipais de Reggio, em 1970, fiquei surpresa com o alto nível de consciência acerca da importância da qualidade dos espaços da escola. [...] Já existia uma clara intuição acerca da relação existente entre a qualidade do espaço e a qualidade do aprendizado.
}

Segundo Hoyuelos $(2004,2006)$, o pensamento e a obra pedagógica de Loris Malaguzzi podem ser analisados com base em três dimensões: ética, estética e política, que o pesquisador espanhol desdobra em princípios, aos quais correspondem estratégias orientadas à efetivação de cada um deles. O tema do ambiente das instituições de educação infantil está presente, especialmente, em um dos princípios

\footnotetext{
${ }^{1}$ Mantivemos o termo "espaço" conforme consta em vários textos consultados, apesar de a concepção se assemelhar ao que consideramos "ambiente" (que é a palavra usada em alguns artigos por Malaguzzi). De modo geral, esses autores não parecem fazer clara distinção entre o uso dos dois termos.
} 
relativos à dimensão ética e em outro referente à dimensão estética. Tomaremos tais princípios para sintetizar essa perspectiva, que vem sendo construída com uma forte base teórica, uma prática aberta ao inusitado e muito compromisso com as crianças.

Um dos princípios relativos à dimensão ética é: educar significa incrementar o número de oportunidades possíveis. ${ }^{2}$ Para melhor entendê-lo, Hoyuelos (2004, p. 204) nos lembra que incrementar oportunidades não significa simplesmente oferecer muitas opções, mesmo porque a possibilidade de explorar o mesmo elemento com novos pontos de vista aumenta as oportunidades educativas. Além disso, nem todas as possibilidades oferecidas às crianças são válidas, pois elas precisam estar adequadas aos desejos e direitos de todas as crianças.

Vale registrar que, do ponto de vista de Malaguzzi, a escola deve ser capaz de proporcionar às pessoas não apenas a "realidade real", mas também a possibilidade de o imaginário fazer-se real, oferecendo mundos insuspeitos, entendendo que o real é apenas uma das possibilidades do possível. Assim, "incrementar o número de oportunidades" significa pensar de um modo distinto - e crítico - daquelas ditadas pelas condições que são impostas num determinado momento histórico.

Na perspectiva de Hoyuelos (2004), quatro estratégias colaboram para a efetivação desse princípio. A primeira é garantir adequada organização da escola, o que, para Malaguzzi, significa que a escola deve ser pequena, acolhedora e agradável, um espaço que permita individualidade, flexibilidade e participação. A segunda é valorizar grupos pequenos - que se constituem em oportunidades de observação, investigação e intervenção do professor que, assim, participa melhor do processo educativo -, nos quais as crianças brincam, comunicam-se, negociam, desenvolvem projetos comuns, estabelecem laços de amizade. A terceira é assegurar o papel do adulto em vários planos: sociopolítico, relacional e cultural, investigativo e relacional didático. ${ }^{3}$ A quarta estratégia é distribuir ou repartir de forma personalizada a responsabilidade. Para o educador italiano, é necessário garantir condições de trabalho que possibilitem aos professores interagirem com cada criança em particular e com o grupo: escutar, observar, realizar investigações e a documentação. Entre tais condições está poder contar com um ambiente bem planejado e agradável para interagirem adequadamente com as crianças, o que, para Malaguzzi, (Hoyuelos, 2004, p. 273), é uma questão ética.

Em relação à dimensão estética, destacamos o princípio que afirma: a escola é um âmbito estético habitável, ${ }^{4}$ o qual complementa as ideias já sintetizadas até o momento. Para melhor entender esse princípio, Hoyuelos (2006) nos lembra que existe uma interferência criadora entre o homem e a realidade que provoca um encontro. Em outras palavras, os mundos físico e social nos afetam profundamente,

\footnotetext{
${ }^{2}$ Os outros princípios são: "a educação tem como base uma imagem de criança, uma imagem que revela a não determinação do ser humano" e "a criança é um sujeito de direitos históricos e culturais".

${ }^{3}$ Malaguzzi tinha um profundo respeito e grandes expectativas em relação aos professores. Nas palavras de Carla Rinaldi (2014, p. 106), ele via os professores "como aqueles que têm o fio [o "fio de Ariadne"], que constroem e constituem os entrelaçamentos e as conexões, a rede de relacionamentos, para transformá-los em experiências significantes de interação e comunicação".

${ }^{4}$ Os dois outros princípios identificados nessa dimensão por Hoyuelos (2006) são: "construir pedagogia é sonhar com a beleza e com o insólito" e "educar supõe desenvolver as capacidades narrativas da sedução estética".
} 
reforçando ou provocando mudanças nos nossos modos de perceber e agir, no nosso senso estético, nas nossas habilidades, nos nossos conhecimentos sobre os outros e sobre nós etc. Assim, as escolhas feitas acerca de que móveis, materiais, livros, brinquedos, gravuras, móbiles, animais ou plantas estarão disponíveis às crianças e adultos, como estarão organizados e como serão usados, fazem muita diferença na qualidade das experiências vividas nos contextos de creches e pré-escolas.

Afirmar que a escola deve ser um lugar habitável também significa que ela seja um espaço de encontro e comunicação (entre pessoas e entre estas e o espaço, os objetos etc.), um lugar dinâmico, interrelacional, qualificado e aberto às múltiplas possibilidades de atuações humanas. Como afirma Gandini (1999, p. 147), esses contextos "tendem a ser agradáveis e acolhedores, contando muito sobre os projetos e as atividades, sobre as rotinas diárias e sobre as pessoas grandes e pequenas que fazem da complexa interação que ocorre ali algo significativo e alegre".

Uma das estratégias para efetivar esse princípio é assumir a concepção da aprendizagem e do desenvolvimento da criança como um motivo de prazer: prazer por aprender, conhecer e entender em interação; prazer pelo próprio esforço em conseguir o que deseja; prazer de se sentir acolhido, respeitado. A outra estratégia é justamente a qualidade do espaço.

É preciso enfatizar com Hoyuelos (2006) que, apesar de ser flexível, aberto a mudanças, o ambiente precisa ter uma identidade clara: a do projeto educativo. Nas palavras de Malaguzzi (2001, p. 64), as escolas de Reggio Emilia

revelan el esfuerzo por integrar las líneas del proyecto educativo, las de la organización del trabajo y las del ambiente arquitectónico e su funcionamiento para conseguir el máximo de circularidad, interdependencia e interacción. Es una tríada sinérgica e complementaria que, por muchas razones, es decisiva para los objetivos y las finalidades de un proyecto que trata de sintonizar - además de los contenidos - también las formas, los tiempos y los lugares donde se hace educación.

Uma ideia muito importante pelas suas decorrências práticas é que, para as grandes potencialidades e riquezas das pessoas se expressarem e se desenvolverem, elas necessitam a participar de um contexto que as solicite e funcione como um interlocutor complexo. Assim, o ambiente deve ser aberto às múltiplas possibilidades de atuação humana, convidando à comunicação, à interação e à investigação. Gandini (2016, p. 316) enfatiza que as estruturas e a cuidadosa escolha e disposição dos materiais pelos professores devem convidar à exploração, a "trocas e interação entre pessoas e coisas em uma rede de possíveis conexões e construções".

Como já aventado, são elementos fundamentais para o educador italiano o prazer e a alegria: a escola tem que ser um lugar prazeroso e alegre. Ele acredita numa alegria vinculada à esperança, que deve ser própria ao ato de educar, como também acreditava Paulo Freire (1992). Trata-se de um otimismo fundado numa crença profunda nas grandes riquezas e possibilidades das crianças, dos adultos e da própria educação. Portanto, é necessário superar o cansaço improdutivo e empobrecedor que certos profissionais e escolas demonstram, o que trai as esperanças das futuras gerações (Malaguzzi, 1992, apud Hoyuelos, 2006, p. 50-51). 


\section{A construção da identidade das crianças e o ambiente}

Mesmo em diferentes abordagens teóricas, é praticamente consenso que as pessoas constroem a ideia de quem são na interação dinâmica estabelecida com o ambiente. Trazemos aqui algumas ideias de Henri Wallon acerca de como essa construção acontece, com o intuito de destacar o importante papel que tem o ambiente, especialmente nos primeiros anos de vida.

Na perspectiva walloniana, no processo longo e complexo de desenvolvimento e construção da sua identidade, o ser humano vive diversas "idades" (ou etapas), caracterizadas por manifestações específicas "cuja significação e papel podem ser uma novidade no comportamento do indivíduo ou da espécie" (Wallon, 1989, p. 507). A primeira grande conquista é a construção do eu corporal, que pressupõe a distinção mais ou menos estável do que constitui o seu próprio corpo, uma vez que, de início, não existem as fronteiras dele com as coisas e com outros corpos nem a consciência de que eles têm uma existência própria - a criança está confundida com eles e não sabe diferenciar a realidade subjetiva da objetiva.

Wallon (1986, p. 164-165) considera que o homem é um ser "essencialmente social" e "o é, não em virtude de contingências externas. Ele o é geneticamente". 5 O outro é um parceiro permanente do eu na vida psíquica. A construção da identidade acontece num processo de progressiva individuação, possível a partir da percepção de si, já referida. Para do outro se diferenciar, por volta do terceiro ano, a criança manifesta um movimento de negação dele, mediante comportamentos de oposição em que, contraditoriamente, a oposição totalmente relativa expressa sua dependência deste outro. Segue-se o interesse em agradar ao outro, a necessidade de sua aprovação, quando a criança "só pode agradar a si mesma se tiver a sensação de poder agradar aos outros, só se admira caso acredite ser admirada" (Wallon, 2007, p. 187). Outro movimento importante nesse momento, que o autor denomina personalismo, é a imitação, em que "a criança se modela conforme as pessoas de seu meio que a atraem" (Wallon, 2007, p. 187). Posteriormente, na puberdade, as conquistas que acontecem no plano da inteligência (especialmente as relativas à superação do sincretismo que marca as etapas anteriores) possibilitam avançar nesse processo de construção do eu.

Ao se tratar da constituição da identidade da criança na perspectiva walloniana, geralmente é enfatizado o papel das relações com as pessoas que fazem parte do contexto no qual ela se desenvolve, uma vez que é um processo profundamente social. No entanto, apesar de destacá-las, o autor insere tais relações num contexto mais amplo: o ambiente.

Para Wallon (1986, p. 170), a maneira pela qual o indivíduo pode satisfazer suas necessidades mais fundamentais depende do meio. ${ }^{6}$ A escola é um dos meios

\footnotetext{
${ }^{5}$ Vale lembrar, com Dantas (1992, p. 92), que o termo geneticamente social se refere à peculiaridade de cada humano ser, desde o início da vida, "radicalmente dependente dos outros seres para subsistir e se construir enquanto ser da mesma espécie"

${ }^{6}$ A noção de meio para Wallon (1986, p. 170) é compreendida como "o conjunto mais ou menos durável de circunstâncias nas quais se desenvolvem existências individuais" ou "o conjunto de circunstâncias físicas, humanas ou ideológicas que confluem num mesmo momento" (p. 178), e leva-nos a associá-la à ideia de ambiente.
} 
nos quais a criança vive e, como acontece em relação aos demais, ela influencia fortemente sua conduta.

Por outro lado, lembramos que a noção de identidade própria é tardia e frágil; de início, a criança mantém uma união global e sincrética com o ambiente. Antes dos três anos, as suas relações são marcadas pela subjetividade e pelas emoções. Então, sem que possam ter consciência disso, as experiências, especialmente as vividas pelos bebês e crianças pequenas, ${ }^{7}$ intervêm nos conhecimentos, nas atitudes e nos valores, inscrevem marcas na construção da consciência de si. Essas experiências são vividas na relação com pessoas, objetos e materiais e acontecem em determinados espaços físicos.

A compreensão de Wallon acerca do papel do meio na constituição da identidade da pessoa parece oferecer subsídios para a defesa de Malaguzzi de que a escola deve ser pequena, acolhedora, agradável e atenta à individualidade. Certamente, experiências de alegria e acolhimento contribuem para o bem-estar, sentimento de aceitação e pertencimento a um grupo. Nessa escola, as crianças encontram elementos que promovem a sua identificação e facilitam a apropriação de aspectos que integram a sua identidade. Entre tais elementos, destaca-se a aprovação e/ou valorização do outro, especialmente do professor quanto às peculiaridades das crianças, desde características físicas até o que elas sentem/ falam/fazem, que são fundamentais para a construção da imagem que têm de si.

Um ambiente que convida à comunicação, interação e investigação, como sustenta o educador italiano, promove, na perspectiva walloniana, as relações com o mundo físico e social, estimulando o desenvolvimento da inteligência e também da pessoa - já que os instrumentos intelectuais possibilitam tanto as distinções e as classificações necessárias ao conhecimento das coisas como das pessoas (Wallon, 1995, p. 277). Para este autor, em cada etapa do desenvolvimento, se estabelece um sistema de relações entre a criança - com os recursos que lhe são então peculiares - e seu meio; e ele conclui que "o meio não pode ser o mesmo para todas as idades", uma vez que constitui "o conjunto de estimulantes sobre os quais se exerce e se regula a atividade da criança" (Wallon, 2007, p. 82). Nesse sentido, é interessante lembrar que na abordagem educacional fundada nas ideias de Loris Malaguzzi há uma grande preocupação de que os ambientes sejam adequados às necessidades e possibilidades particulares de cada momento do desenvolvimento da criança. Como expressa Gandini (1999, p. 155), "os materiais e os objetos que estão no espaço onde as crianças passam muitas horas foram escolhidos ou construídos de acordo com o contexto no qual serão usados, com uma consideração quanto ao modo como as crianças reagirão a eles". ${ }^{8}$

Como já foi referido, o ambiente expressa ideias e sentimentos acerca da criança, da educação e da sociedade. Tais ideias e sentimentos são apropriados pelas

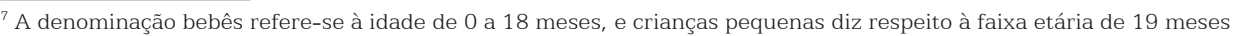
a 3 anos e 11 meses.

${ }^{8}$ Vale lembrar, no entanto, que, para o educador italiano, além dos materiais, objetos etc. que o ambiente contém, é preciso cuidar da forma como os adultos se relacionam com as crianças, pois isso é o que as motiva, fortemente, a aprender. Assim, o mais importante é construir "un terreno que haga emergir los acoplamientos estructurales entre lo cognitivo, lo relacional y lo afectivo" (Malaguzzi, 2001, p. 55), uma perspectiva coincidente com a abordagem walloniana.
} 
crianças, transformando-se em ingredientes importantes no processo de construção da sua identidade.

As interações, no contexto da educação infantil, são primordiais nesse processo, especialmente que acontecem entre os adultos e as crianças e entre elas próprias. Mas não se pode esquecer de que as interações não ocorrem isoladas do contexto físico: os quadros, os móbiles, as fotografias, os brinquedos, os livros de literatura infantil -, todos os elementos que compõem o ambiente frequentado pelas crianças pequenas se constituem mediadores para as ações e aprendizagens delas. Quanto menores elas forem, maior o poder de deixar marcas e influenciar a consciência que têm de si. As experiências que as crianças vivem no contexto da creche ou pré-escola são, portanto, afetadas pelo conjunto de elementos que configuram esses ambientes.

Nesse sentido, é preciso lembrar que, no início da vida, a dimensão afetiva - particularmente as emoções - não só impregna, mas está na base da consciência de si e do outro. Como afirma Wallon (2007, p. 182-183), "quanto às primeiras tomadas de contato entre o sujeito e o ambiente, estas são de ordem afetiva: são as emoções"; elas marcam as impressões que se fundem numa espécie de equivalência mútua. Portanto, para que cada criança construa uma consciência positiva acerca de si, ela precisa ter a possibilidade de viver experiências que lhe assegurem que a sua singularidade é aceita e valorizada, pois as analogias com as quais o pensamento infantil opera são extraídas da experiência usual.

A concepção do meio como instrumento para o desenvolvimento da criança também é evidenciada quando Wallon (1986, p. 169) trata do papel dos meios e dos grupos na psicogênese da criança, por exemplo, ao sustentar a ideia de que:

\footnotetext{
A sociedade coloca o homem em presença de novos meios, novas necessidades e novos recursos que aumentam suas possibilidades de evolução e diferenciação individual. A constituição biológica da criança, ao nascer, não será a única lei de seu destino posterior. Seus efeitos podem ser amplamente transformados pelas circunstâncias sociais de sua existência [...].
}

Se desejamos que as experiências vividas no contexto da educação infantil contribuam para alimentar em todas as crianças um sentimento de segurança e de pertencimento, de acolhimento às suas singularidades, precisamos lhes oferecer, nas suas experiências cotidianas, elementos para se reconhecerem e valorizarem suas peculiaridades (físicas, culturais, religiosas etc.), assim como as das demais crianças e dos adultos. Nesse sentido, é necessário, por exemplo, possibilitar a bebês e crianças pequenas o contato frequente com bonecas, desenhos e fotografias de negros, nisseis, indígenas, pessoas cadeirantes, cegas, surdas, com Síndrome de Down etc.; contar-lhes histórias nas quais tenham papéis importantes e positivos não apenas personagens brancos, mas também os diversos tipos que compõem o rico legado étnico-racial brasileiro, bem como pessoas com algum tipo de deficiência. Tal contexto incrementaria o número de oportunidades possíveis na visão de Malaguzzi e contribuiria para que as crianças construíssem 
novas formas de sociabilidade e de subjetividade comprometidas com a ludicidade, a democracia, a sustentabilidade do planeta e com o rompimento de relações de dominação etária, socioeconômica, étnico-racial, de gênero, regional, linguística e religiosa. (Brasil. CNE, 2009, art.7º, inc. V).

Vale ressaltar que esse ambiente deve contar com uma imagem de criança competente, ativa e curiosa, de tal forma que possa interagir de maneira criativa e relativamente autônoma com tais elementos, assim como com professores e famílias. Portanto, uma meta importante é "assegurar que os três sujeitos - crianças, educadores e pais - possam efetivamente habitar o espaço, mas acima de tudo, garantir o bem-estar como criadores e usuários desse espaço e do que acontece ali" (Rinaldi, 2014, p. 160). A ação das crianças, desafiadas pela presença e disposição de diferentes objetos e materiais criteriosamente disponibilizados pelo professor, ganha protagonismo.

\section{Considerações finais}

Julgamos importante destacar que a forma como os adultos organizam os materiais e o espaço no qual trabalham com bebês e crianças pequenas expressa suas concepções acerca desses sujeitos e do seu papel nas aprendizagens e desenvolvimento deles. $\mathrm{Na}$ abordagem italiana, são fundamentais as concepções de criança como ativa, potente, curiosa, criativa, que atribui significados e os partilha. Além disso, o espaço deve contribuir positivamente para que a criança possa ser tudo o que pode ser e, sentindo-se segura e acolhida, se desenvolva em todos os aspectos.

A obra de Loris Malaguzzi pode provocar reflexões sobre o ambiente que ofertamos às crianças, suas famílias e os profissionais que trabalham em instituições de educação infantil. Do mesmo modo, as ideias de Henri Wallon acerca da construção da identidade pela pessoa e da função do meio na psicogênese da criança trazem elementos importantes para a compreensão do papel do ambiente nesse processo.

O uso dos espaços e materiais é dinâmico e o compromisso dos profissionais com as aprendizagens, o desenvolvimento, o bem-estar e os direitos das crianças, aliado à criatividade e à sensibilidade para identificar e atender às demandas infantis, podem contribuir para minimizar os limites colocados por políticas que menosprezam a educação das crianças. Um passo importante nessa direção é a consciência de que, ao expressar e favorecer o projeto pedagógico, o ambiente também participa da construção da identidade de pessoas e de sociedades com determinadas características. Nesse sentido, Malaguzzi (1975, apud Hoyuelos, 2006 p. 84) acredita que temos de decidir que sociedade nós desejamos para que a escola - com sua arquitetura, seus objetos, sua decoração e seus móveis - torne-se cúmplice dessa ideia. 


\section{Referências bibliográficas}

AgOstinho, K. A. O espaço da creche: que lugar é este? 2003. $164 \mathrm{f}$. Dissertação (Mestrado em Educação) - Centro de Ciências da Educação, Universidade Federal de Santa Catarina, Florianópolis, 2003.

BARBOSA, M. C. S. Por amor e por força: rotinas na educação infantil. Porto Alegre: Artmed, 2006.

BARBOSA, M. C. S.; HORN, M. G. S. Organização do espaço e do tempo na educação infantil. In: CRAIDY, C.; KAERCHER, G. (Org.). Educação infantil: pra que te quero? Porto Alegre: Artmed, 2001. p. 67-80.

BRASIL. Conselho Nacional de Educação (CNE). Conselho Pleno (CP). Resolução $\mathrm{n}^{\mathrm{o}}$ 1, de 17 de junho de 2004. Institui diretrizes curriculares nacionais para a educação das relações étnico-raciais e para o ensino de História e Cultura AfroBrasileira e Africana. Diário Oficial da União, Brasília, 22 jun. 2004. Seção 1, p. 11.

BRASIL. Conselho Nacional de Educação (CNE). Câmara de Educação Básica (CEB). Resolução no 5, de 17 de dezembro de 2009. Fixa as diretrizes curriculares nacionais para a educação infantil. Diário Oficial da União, Brasília, 18 dez. 2009. Seção 1, p. 18.

DANTAS, H. A afetividade e a construção do sujeito na psicogenética de Wallon. In: LA TAILlE, Y.; OLIVEIRA, M. K.; DANTAS, H. Piaget, Vygotsky, Wallon: teorias psicogenéticas em discussão. São Paulo: Summus, 1992. p. 85-100.

EVANGELISTA, A. S. Concepções e expectativas de crianças e de profissionais sobre o espaço educacional na educação infantil. 2016. 265 f. Dissertação (Mestrado em Educação) - Faculdade de Ciências e Tecnologia, Universidade Estadual Paulista, Presidente Prudente, 2016.

FORNEIRO, L. I. A organização dos espaços na educação infantil. In: ZABALZA, M. A. Qualidade em educação infantil. Porto Alegre: Artes Médicas, 1998. p. 229-279.

FREIRE, P. Pedagogia da esperança. Rio de Janeiro: Paz e Terra, 1992.

GANDINI, L. Espaços educacionais e de envolvimento pessoal. In: EDWARDS, C.; GANDINI, L.; FORMAN, G. As cem linguagens da criança: a abordagem de Reggio Emilia na educação da primeira infância. Porto Alegre: Artmed, 1999.

GANDINI, L. Conectando-se por meio dos espaços de cuidado e de aprendizagem. In: EDWARDS, C.; GANDINI, L.; FORMAN, G. As cem linguagens da criança: a experiência de Reggio Emilia em transformação. Porto Alegre: Penso, 2016. v. 2, p. 315-336.

HORN, M. G. S. Sabores, cores, sons, aromas: a organização dos espaços na educação infantil. Porto Alegre: Artmed, 2004. 
HOYUELOS, A. La ética en el pensamiento y obra pedagógica de Loris Malaguzzi. Barcelona: Octaedro; Rosa Sensat, 2004.

HOYUELOS, A. La estética en el pensamiento y obra pedagógica de Loris Malaguzzi. Barcelona: Octaedro; Rosa Sensat, 2006.

MALAGUZZI, L. La educación infantil en Reggio Emilia. Barcelona: Octaedro; Rosa Sensat, 2001.

OLIVEIRA-FORMOSINHO, J. Educação das crianças até aos três anos: algumas lições da investigação. In: OLIVEIRA-FORMOSINHO, J.; AZEVEDO, A. Pedagogia em creche: qualidade, documentação, diversidade. Porto: Porto Editora, 2011.

RINALDI, C. O espaço da infância. In: RINALDI, C. Diálogos com Reggio Emilia: escutar, investigar e aprender. São Paulo: Paz e Terra, 2014.

WALLON, H. Os meios, os grupos e a psicogênese da criança. In: WEREBE, M. J.; NADEL-BRULFERT, J. Henri Wallon. São Paulo: Ática, 1986. p. 168-178.

WALLON, H. As origens do pensamento na criança. São Paulo: Manole, 1989.

WALLON, H. As origens do caráter na criança. São Paulo: Nova Alexandria, 1995.

WALLON, H. A evolução psicológica da criança. São Paulo: Martins Fontes, 2007.

Silvia Helena Vieira Cruz, doutora em Psicologia Escolar e do Desenvolvimento Humano pelo Instituto de Psicologia da Universidade de São Paulo (IP-USP), com pós-doutorado na Universidade do Minho, em Braga, Portugal, é professora titular da Faculdade de Educação da Universidade Federal do Ceará (Faced-UFC).

silviavc@uol.com.br

Rosimeire Costa de Andrade Cruz, doutora em Educação pela Universidade Federal do Ceará (UFC), é professora associada da Faculdade de Educação (Faced-UFC).

rosimeireca@yahoo.com.br

Recebido em 30 de março de 2017

Aprovado em 25 de agosto de 2017 